\title{
APLIKASI PEMETAAN DAN PENCARIAN BENGKEL BANJARMASIN BERBASIS ANDROID
}

\author{
Sefto Pratama ${ }^{1)}$ \\ ${ }^{1}$ Fakultas Teknologi Informasi, Universitas Islam Kalimantan Muhammad Arsyad Al Banjari (Sefto Pratama) \\ email : Seftopratama.bjm@gmail.com
}

\begin{abstract}
Abstrak
Informasi fasilitas bengkel dan tambal ban menjadi hal yang sangat penting apabila ingin atau sedang berpergian, kondisi dan kelayakan kendaraan yang kita gunakan dalam berpergian menjadi alat transportasi utama kita, seringnya terjadi kecelakaan yang diakibatkan oleh rusaknya mesin maupun ban kendaraan yang bocor berpengaruh kepada peningkatan jumlah kecelakaan di jalan, Direktorat Lalu Lintas Polda Metro Jaya mencatat jumlah kecelakaan yang terjadi selama periode Januari hingga November 2018 meningkat di banding dengan tahun 2017 yaitu pada tahun 2018 sebanyak 5400 kejadian, sementara pada tahun 2017 5140. Sulitnya dalam mencari bengkel atau tempat tambal ban ketika kita sedang berada di tengah perjalanan dan mengalami masalah pada kendaraan kita. Maka dari itu peneliti memilih untuk membuat sebuah aplikasi yang dapat membantu kita dalam mengetahui letak bengkel dan tambal ban terdekat dari posisi kita, selain itu aplikasi ini menyajikan informasi lengkap tentang bengkel yang tersedia. Tujuan jangka panjang dari aplikasi ini adalah agar dapat membantu masyarakat Banjarmasin khususnya pengguna smartphone dalam mencari bengkel di area Kota Banjarmasin secara mudah cepat dan tepat sesuai dengan informasi yang tersedia.
\end{abstract}

Keywords: Aplikasi Pemetaan, Pencarian, Bengkel, Tambal Ban, Android

\section{PENDAHULUAN}

Di era modern sekarang ini pemanfaatan smartphone bukan hanya sebagai alat komunikasi saja, namun lebih dari itu. Kecanggihan dari sebuah smartphone memungkinkan bagi penggunanya dapat mengakses berbagai macam informasi, smartphone juga dilengkapi dengan fasilitas yang canggih seperti kamera dengan resulisi tinggi, GPS atau Global Positioning System yaitu gunanya untuk mengetahui letak suatu tempat dari permukaan bumi dengan bantuan penyelaras sinyal satelit. Dengan bantuan GPS kita dapat mengetahui letak suatu tempat yang ingin dituju secara cepat, tepat dan akurat.

Sistem operasi Android pada smartphone telah terpasang Global Positioning System
(GPS), yang artinya pengguna smartphone dapat mengetahui secara langsung dimana posisinya berada. Teknologi Global Positioning System (GPS) juga dapat membantu penggunanya dalam memandu untuk mengetahui arah atau tempat yang ingin di datangi, salah satunya adalah bengkel area Kota Banjarmasin. Pada saat pengendara mobil ataupun motor mengalami masalah kerusakan ditengah perjalanan seperti kerusakan pada lampu, radiator, air cooler, busi, dan permasalahan mesin lainnya, seringkali pengendara yang bukan berasal dari kota Banjarmasin.

Berdasarkan dari permasalahan diatas maka perlu dibuat sebuah "Aplikasi Pemetaan dan Pencarian Bengkel Area Kota 
Banjarmasin Berbasis Android" menurut informasi yang sudah disediakan diaplikasi tersebut pengguna dengan mudah dapat menemukan letak bengkel kapanpun dan dimanapun diarea Kota Banjarmasin, selain itu juga pengguna dapat melihat secara rinci apa saja yang menjadi fasilitas yang diberikan oleh bengkel tersebut.

\section{METODE PENELITIAN}

Pada penelitian ini penulis menggunakan beberapa metode pengumpulan data sebagai berikut :

a. Metode Observasi

Observasi atau pengamatan merupakan salah satu teknik pengumpulan data atau fakta yang cukup efektif untuk mempelajari suatu sistem. Observasi yang dilakukan yaitu datang langsung melihat dan mendata bengkel di area Kota Banjarmasin.

b. Metode Wawancara

Wawancara merupakan salah satu teknik pengumpulan data yang penting dan banyak dilakukan dalam pengembangan Aplikasi. Wawancara dilakukan dengan pemilik bengkel untuk mengumpulkan data secara tatap muka langsung dengan orang yang diwawancarai. Adapun orang-orang yang diwawancarai adalah yang mempunyai bengkel diarea Kota Banjarmasin.

Analisis sistem adalah suatu proses mengumpulkan dan menginterpretasikan kenyataan-kenyataaan yang ada, mendiagnosa persoalan dan menggunakan keduanya untuk memperbaiki sistem. Pada tahap ini penulis lakukan adalah :

a. Mengidentifikasi masalah untuk mendapat pengertian sebenarnya dari masalah yang dihadapi yaitu dengan mengidentifikasikan penyebab masalah dan bagaimana langkah untuk menyelesaikannya.

b. Memahami sistem kerja yang ada dengan mengumpulkan data hasil penelitian dan memahami sistem yang ada.

c. Menganalisa kelemahan sistem dan kebutuhan informasi

\section{Tahapan Penelitian}

Berikut ini adalah desain penelitian yang akan dilakukan :

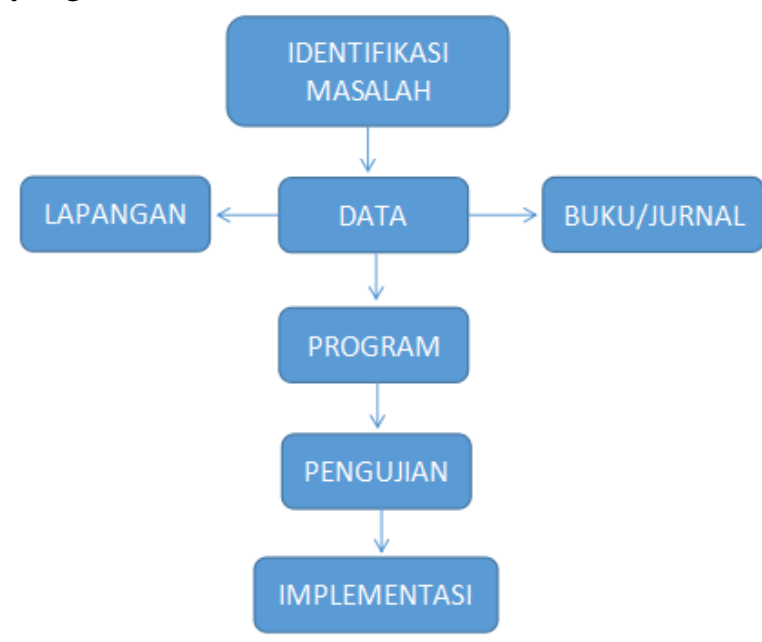

Gambar 1, Desain Penelitian

\section{Objek Penelitian}

Objek penelitian ini dilakukan di Bengkel yang berada di area Kota Banjarmasin.

\section{Metode Pengumpulan Data}

Pada penelitian ini penulis menggunakan beberapa metode pengumpulan data sebagai berikut :

1. Metode Observasi

Observasi atau pengamatan merupakan salah satu teknik pengumpulan data atau fakta yang cukup efektif untuk mempelajari suatu sistem. Observasi adalah pengamatan langsung para pembuat keputusan berikut lingkungan fisiknya atau pengamatan langsung suatu kegiatan yang sedang berjalan. Pada tahap ini penulis melakukan pengamatan terhadap kegiatan, proses, dan alur masuk dan bagaimana sebuah sistem pencatatan berjalan.

2. Metode Wawancara

Wawancara merupakan salah satu teknik pengumpulan data yang penting dan banyak dilakukan dalam pengembangan Aplikasi. Wawancara memungkinkan analis sistem sebagai pewawancara untuk mengumpulkan data secara tatap muka langsung dengan orang yang 
diwawancarai. Adapun orang-orang yang diwawancarai adalah Masyarakat pengguna kendaraan bermotor dan pemilik bengkel yng berada di area Kota Banjarmasin.

\section{Tahap-Tahap Pembuatan Sistem}

Dalam pengembangan sistem ini, ada beberapa tahapan yang harus dilakukan. Adapun tahapan tersebut adalah sebagai berikut:

\section{Analisis Sistem yang berjalan}

a) Tidak adanya system atau aplikasi yang menangani masalah apabila terjadi kendala di kendaraan pada saat diperjalanan.

b) Sulitnya para pengendara mobil maupun motor pada saat di jalan untuk menemukan bengkel terdekat.

\section{Analisis Kebutuhan Sistem}

a) Saat ini masih belum ada sistem aplikasi yang dapat memudahkan para pengguna kendaraan bermotor dalam mencari bengkel terdekat.

b) Aplikasi maps yang tersedia sekarang masih kurang jelas dan lengkap dalam menginformasikan informs bengkel yang tersedia.

c) Dari permasalahan diatas maka dibutuhkan sebuah sistem aplikasi

\section{Use Case Diagram}

Berikut skema alur urutan proses sistem secara logika rancangan sistem aplikasi :

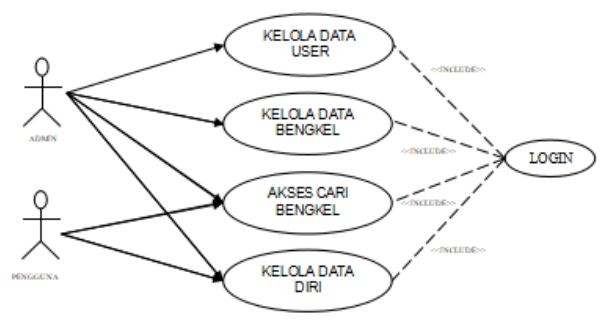

yang dapat membantu dalam mengelola data bengkel yang tersedia di area Kota Banjarmasin.

\section{Perancangan Sistem}

Proses perancangan dalam pembuatan Aplikasi sangat penting untuk dilakukan, guna terciptanya Aplikasi yang bias berjalan dengan lancer dan bermanfaat, kali ini perancangan menggunakan cara :

\section{Waterfall Aplikasi Pemetaan dan Pencarian Bengkel Berbasis Android.}

Berikut skema alur urutan proses dalam persiapan pembuatan Aplikasi Pemetaan dan Pencarian Bengkel Area Kota Banjarmasin Berbasis Android.

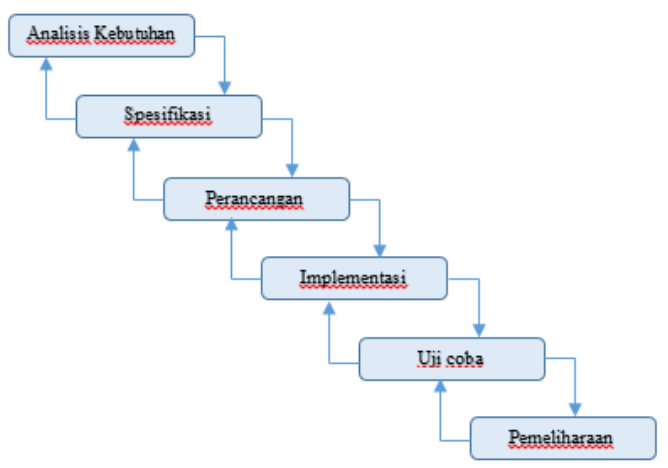

Gambar 2 Metode Waterfall Aplikasi Pemetaan dan Pencarian Bengkel Area Kota Banjarmasin Berbasis Android

Gambar 3, Use Case Diagram Aplikasi Pemetaan dan Pencarian Bengkel Area Kota Banjarmasin Berbasis Android

\section{Rancangan Tampilan Pengguna}

Rancangan interface tampilan awal Aplikasi Pemetaan dan Pencarian Bengkel Area Kota Banjarmasin Berbasis Android. 


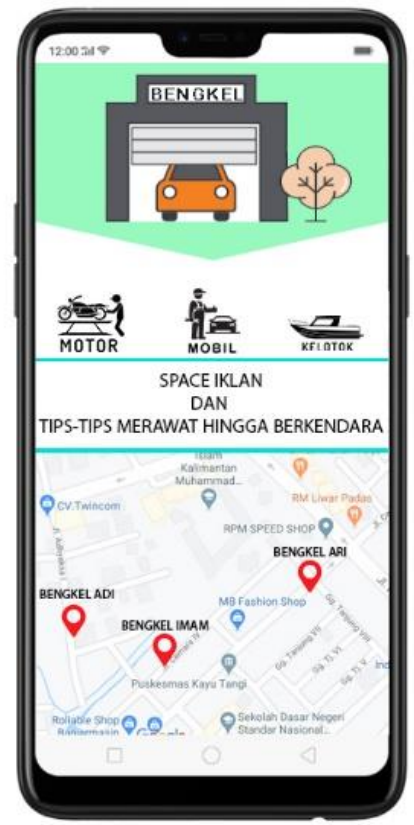

Gambar 4 interface halaman awal pada Aplikasi Pemetaan dan Pencarian Bengkel Area Kota Banjarmasin Berbasis Android

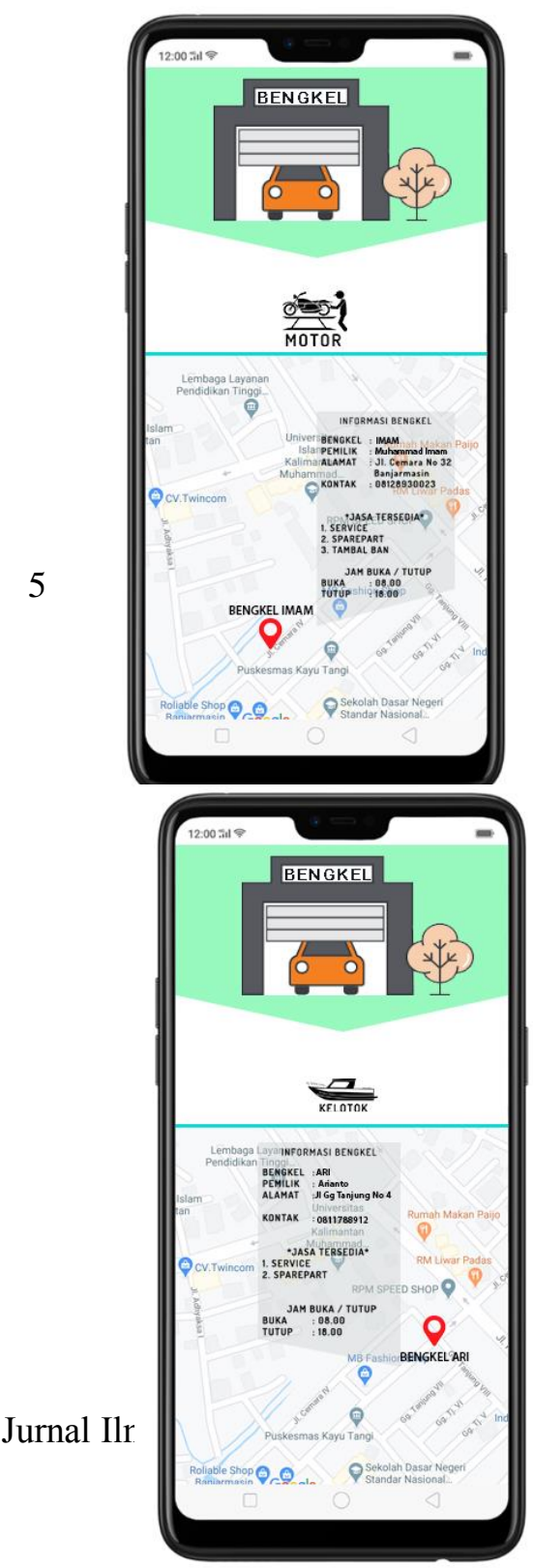

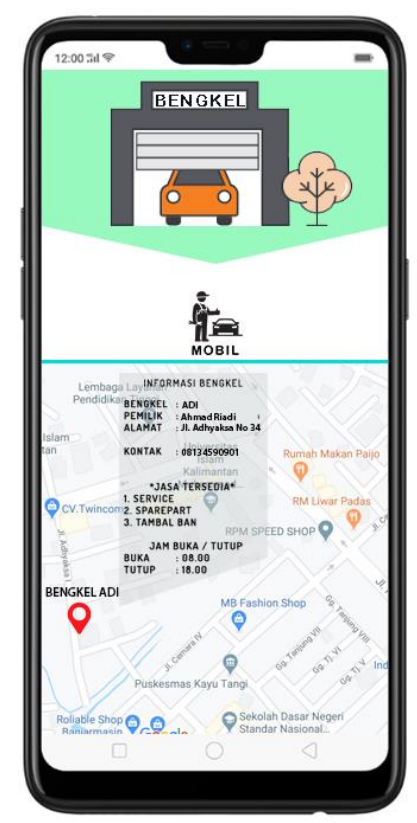

Gambar 6 interface halaman pencarian mobi; pada Aplikasi Pemetaan dan Pencarian Bengkel Area Kota Banjarmasin Berbasis Android

Gambar interface halaman
Pencarian Motor pada Aplikasi Pemetaan dan Pencarian Bengkel Area Kota Banjarmasin
Gambar 7 interface halaman Pencarian Kelotok pada Aplikasi Pemetaan dan Pencarian Bengkel Area Kota Banjarmasin 


\section{HASIL DAN PEMBAHASAN}

\section{Rancangan Menu}

Berikut ini adalah Rancangan Menu Admin Aplikasi Pemetaan dan PencarianBengkel Area Kota Banjarmasin Berbasis Android:

\section{Login}

2. Halaman Awal

3. Data Benkel

- Lihat Data Bengkel

- Edit Data Bengkel

- Hapus Data Bengkel

\section{Rancangan Tampilan Admin}

Berikut ini adalah tampilan rancangan Menu Admin :

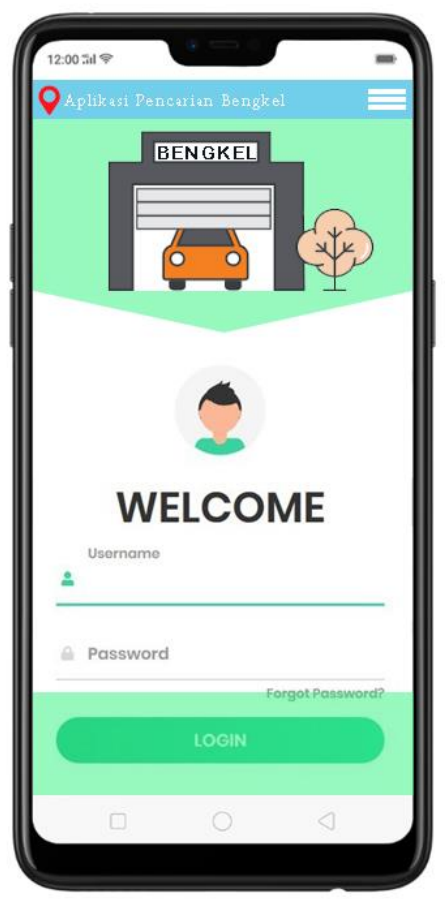

Gambar 8 interface halaman login Admin pada Aplikasi Pemetaan dan Pencarian Bengkel Area Kota Banjarmasin

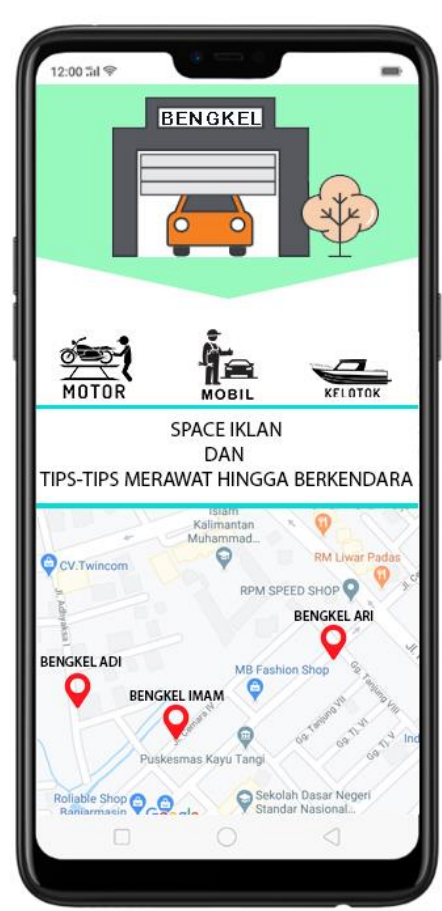

Gambar 9 interface halaman awal Admin pada Aplikasi Pemetaan dan Pencarian Bengkel Area Kota Banjarmasin

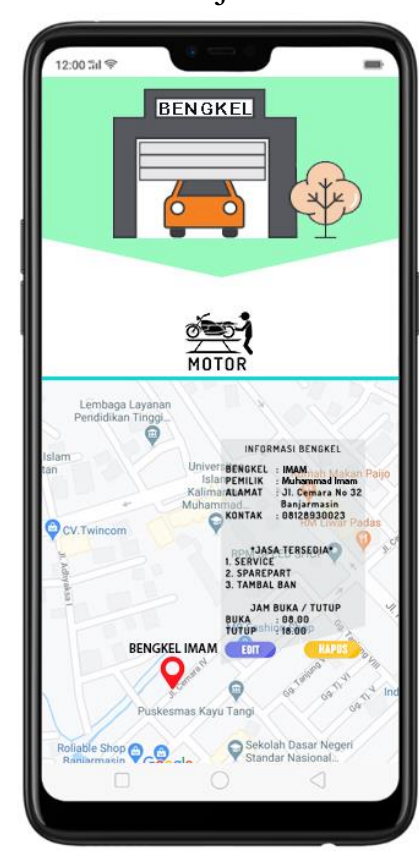

Gambar 10 interface Admin halaman edit/hapus data bengkel motor pada Aplikasi Pemetaan dan Pencarian Bengkel Area Kota Banjarmasin 
Gambar 12 interface Admin halaman edit/hapus data bengkel kelotok pada Aplikasi Pemetaan dan

Pencarian Bengkel Area Kota Banjarmasin

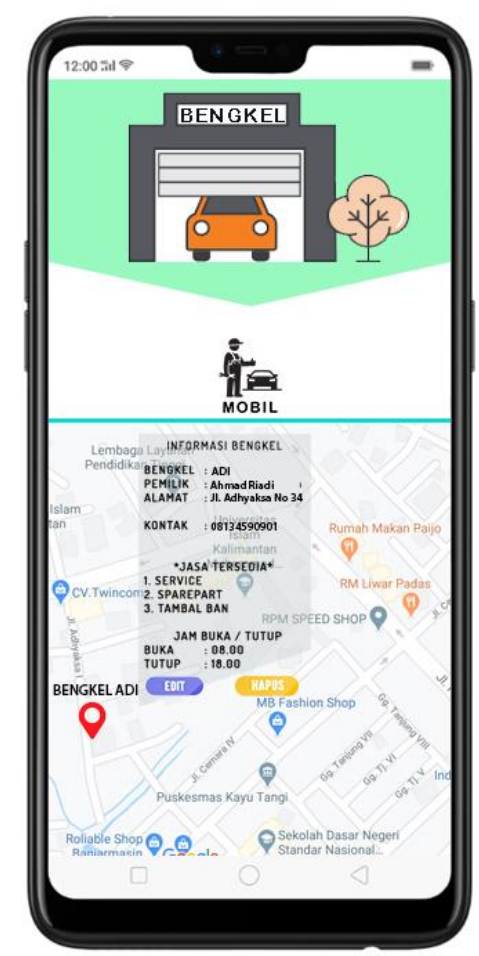

Gambar 11 interface Admin halaman edit/hapus data bengkel mobil pada Aplikasi Pemetaan dan Pencarian Bengkel Area Kota Banjarmasin

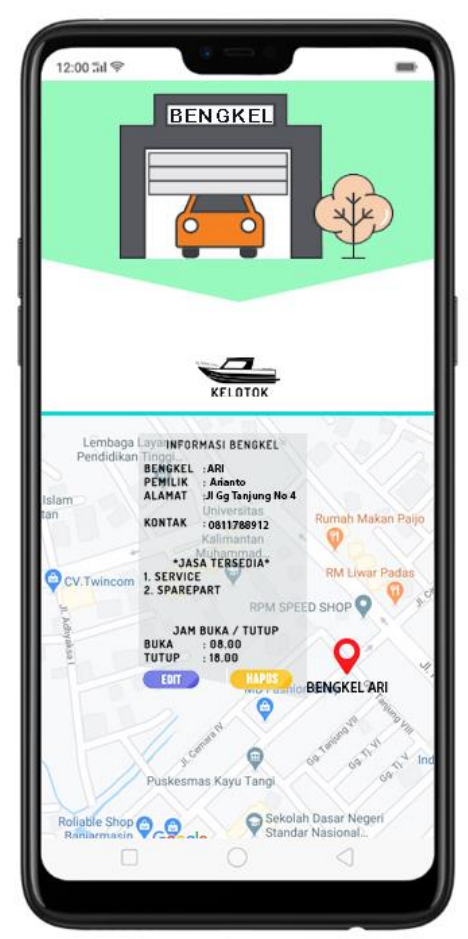

\section{KESIMPULAN}

Adapun kesimpulan dari penelitian ini adalah

a. Dengan adanya aplikasi pemetaan dan pencarian bengkel ini dapat mempermudah masyarakat khususnya bagi pengguna Smartphone dalam mencari atau mengetahui keberadaan bengkel yang ada didekatnya apabila terjadi masalah pada kendaraannya.

b. Dan bagi pemilik bengkel agar dapat menjadi tempat promosi bengkelnya secara online berbasis Android yang bias diakses dimana saja dan kapan saja.

\section{REFERENSI}

[1]. Cahyono, L. A., Winarno, W. W., \& Nugroho, H. A. (2015). Virtualisasi medis: Analisis kecenderungan masyarakat mencari informasi kesehatan di internet. SEMNASTEKNOMEDIA ONLINE, 3(1), 1-2.

[2]. Dasar, K. (2012). Sistem informasi kesehatan.

[3]. Herlambang, T. W., Aknuranda, I., \& Saputra, M. C. (2017). Pengembangan Sistem Informasi Kesehatan Berbasis Web Berdasarkan Model Organisasi Dan Manajemen Kesehatan Primer "ANDAL". Jurnal Pengembangan Teknologi Informasi dan Ilmu Komputer e-ISSN, 2548, 964X.

[4]. Pratama, S. (2019). Aplikasi Job Fair Berbasis Web Pada Dinas Sosial Tenaga Kerja dan Transmigrasi Kalimantan Selatan. Technologia: Jurnal Ilmiah, 10(1), 47-52. 
[5]. Pratama, S. (2016). Penerapan Aplikasi Posyandu Mawar Kelurahan Simpang Empat. Technologia: Jurnal Ilmiah, 7(4).

[6]. Pratama, S. (2016). Penerapan Sistem Informasi Posyandu Mawar Kelurahan Simpang Empat. Technologia: Jurnal Ilmiah, 7(4).

[7].

[8]. Sanjoyo, R. (2007). Sistem Informasi Kesehatan. KTI. Yogyakarta: UGM.

[9]. Wahono, B. B. (2015). Perancangan tatakelola teknologi informasi untuk peningkatan layanan sistem informasi kesehatan (studi kasus dinas kesehatan kabupaten jepara). Simetris: Jurnal Teknik Mesin, Elektro dan Ilmu Komputer, 6(1), 101-110. 